\title{
The Effect of Autotransfusion System in Minimally Invasive Total Knee Arthroplasty
}

\author{
Dong-Jun Ha, MD, Hyung-Seok Lee, MD, Jeong-Han Ha, MD, Jong-Yup Kim, MD, and Dae-Won Jung, MD \\ Department of Orthopedic Surgery, Maryknoll Hospital, Busan, Korea
}

Purpose: To evaluate the effect of autotransfusion system in minimally invasive total knee arthroplasty (TKA).

Materials and Methods: Seventy-one patients who underwent unilateral minimally invasive TKA between October 2009 and June 2010 were selected. The first group included 36 patients who received standard vacuum drainage and the second group, 35 patients who underwent autologous retransfusion drainage. In the first group, allogeneic blood transfusion was performed if the postoperative hemoglobin level was $<7.0 \mathrm{~g} / \mathrm{dL}$ or $7.0-8.0$ $\mathrm{g} / \mathrm{dL}$ with the presence of a medical complication and an anemic symptom. The second group received autotransfusion and allogeneic transfusion additionally according to the same criteria. Changes in the pre- and postoperative hemoglobin level, amount of auto- or allotransfusion, and frequency of allogeneic transfusion were assessed.

Results: Allogeneic transfusion was required in 13 patients (36.1\%) in the first group and four patients (11.4\%) in the second group. The mean allogeneic transfusion volume was significantly low in the second group compared to the first group ( $64.4 \mathrm{~mL} v \mathrm{~s} .278 .9 \mathrm{~mL} ; \mathrm{p}<0.05)$. The hemoglobin level on the 1st postoperative day compared to the preoperative level decreased by $22.6 \%$ in the first group and $11.7 \%$ in the second group. The postoperative hemoglobin level was higher in the second group $(\mathrm{p}<0.05)$.

Conclusions: Minimally invasive unilateral TKA with an autotransfusion system can be beneficial in patients with no medical complications because of the decreased allogeneic transfusion.

Keywords: Knee, Total knee arthroplasty, Minimal invasive surgery, Autotransfusion

\section{Introduction}

Blood transfusion is required in $18 \%$ to $95 \%$ of the patients ${ }^{1-3)}$ after total knee arthroplasty (TKA) due to massive hemorrhage caused by intraoperative damage to muscles and synovial membrane, bone resection, or extraperiosteal bleeding. Unfortunately, allogeneic transfusion has been associated with various problems, such as blood type incompatibility, early/ late immune responses, immunosuppression, increased risk

Received August 20, 2012; Revised (1st) October 18, 2012;

(2nd) March 21, 2013; Accepted April 10, 2013

Correspondence to: Dae-Won Jung, MD

Department of Orthopedic Surgery, Maryknoll Hospital, 121 Junggu-ro, Jung-gu, Busan 600-730, Korea

Tel: +82-51-461-2376, Fax: +82-51-463-1194

E-mail: daewon0809@hotmail.com

This is an Open Access article distributed under the terms of the Creative Commons Attribution Non-Commercial License (http://creativecommons.org/licenses/by-nc/3.0/) which permits unrestricted non-commercial use, distribution, and reproduction in any medium, provided the original work is properly cited. of infection, clotting factor deficiency, and transmission of infectious diseases ${ }^{4-7)}$. Thus, efforts have been made to reduce the use of blood transfusion in the orthopedic field. Meanwhile, postoperative autologous transfusion has been considered advantageous in avoiding the aforementioned side effects as well as cost-effective ${ }^{8,9)}$. In addition, with the recent development of minimally invasive surgery (MIS) techniques, TKA can be performed through a minimal surgical incision causing reduced soft tissue damage and bleeding and enables early postoperative rehabilitation $^{10,11)}$. The purpose of this study is to investigate if the employment of an autotransfusion system in TKA using an MIS technique would reduce the need for allogeneic transfusion.

\section{Materials and Methods}

\section{Patients}

A total of 100 patients underwent unilateral TKA using an MIS technique at our institution between October 2009 and June 2010. Of the patients, excluding those who had coagulopathy or sequential bilateral TKA or received a stem or augmentation 
prosthesis, 71 patients were reviewed retrospectively in this study. Thirty-six patients who underwent standard vacuum drainage were classified into group I and the remaining 35 patients who were treated with autologous retransfusion drainage into group II. In group I, the mean age was 67.7 years (range, 54 to 80 years), the mean weight was $60.92 \mathrm{~kg}$ (range, 41.0 to $98.0 \mathrm{~kg}$ ), the mean preoperative hemoglobin level was $12.8 \mathrm{~g} / \mathrm{dL}$ (range, 9.9 to 14.7 $\mathrm{g} / \mathrm{dL}$ ), and the male to female ratio was 3:33. In group II, the mean age was 66.8 years (range, 50 to 78 years), the mean weight was $60.1 \mathrm{~kg}$ (range, 39.0 to $92.0 \mathrm{~kg}$ ), the mean preoperative hemoglobin level was $13.0 \mathrm{~g} / \mathrm{dL}$ (range, 11.0 to $15.5 \mathrm{~g} / \mathrm{dL}$ ), and the male to female ratio was 2:34, showing no statistically significant difference with group I $(\mathrm{p}=0.312)$. The preoperative diagnosis was degenerative arthritis in all patients in group I and in 34 patients in group II, and the arthritis was combined with osteonecrosis of the distal femur and proximal tibia in the remaining two patients in group II.

\section{Surgical Technique}

All the operations were performed by the same surgeon. A tourniquet was placed around the proximal femur and inflated to $200 \mathrm{mmHg}$ above systolic blood pressure. An 8 to $12 \mathrm{~cm}$ skin incision was made in an anterior midline approach and the joint was exposed through a midvastus approach. Bone resection was performed using the measured resection technique based on intramedullary alignment of the femur and extramedullary alignment of the tibia. Posterior cruciate ligament was resected in all knees. Femoral and tibial components were fixated with bone cement. Patellar resurfacing was performed in 28 cases in group I and in 27 cases in group II. A drill hole in the distal femur for insertion of an intramedullary guide was filled with an autologous bone graft obtained from the resected tibia before tibial component cementing. The femoral component used was in the form that the entrance of the intramedullary cavity is closed. The operation was completed in one tourniquet period in all cases. The tourniquet was deflated when the cement for tibial and femoral components completely hardened. If bleeding occurs after tourniquet release, hemostasis was performed. A drain was inserted into the joint in both groups before wound closure and sterilization of the surgical site.

Postoperatively, a $400 \mathrm{~mL}$ standard vacuum drain, the Barovac Closed Wound Drainage Evacuator System (PP/PS type, Sewoon Medical, Seoul, Korea) was used under a mean negative pressure of $90 \mathrm{mmHg}$ in group I. In group II, the Hemovac Autotransfusion System (HAS, Autotransfusion System, Zimmer, Warsaw, IN, USA) (Fig. 1) was used and the drained blood was

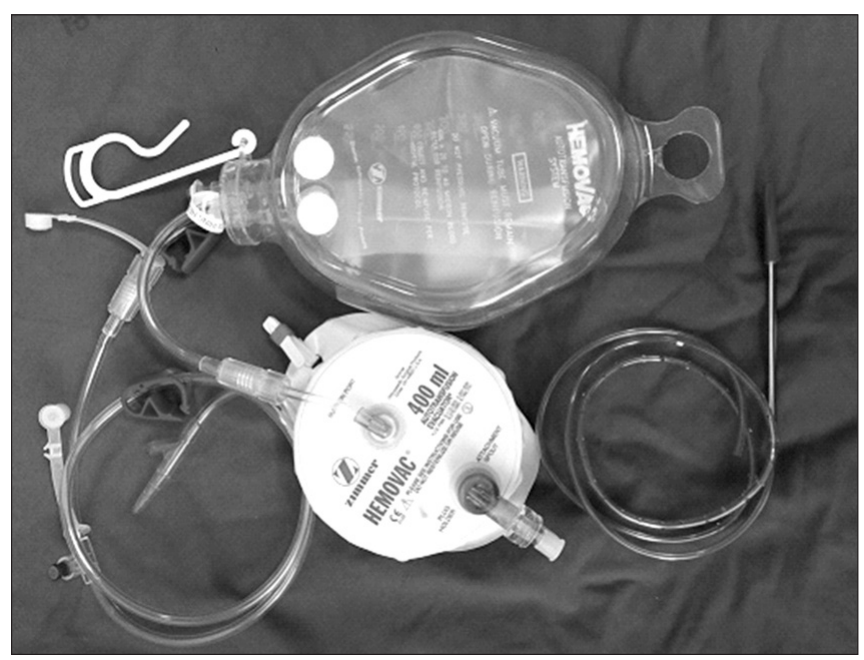

Fig. 1. The Hemovac Autotransfusion System was composed of autotransfusion evacuator, evacuator tubing, and exudate collection bag.

transferred through filters (a $200 \mu \mathrm{m}$ small prefilter and a 0.45 $\mu \mathrm{m}$ air filter) into the reinfusion bag. The drain was removed on the 3rd postoperative day in group I. In groups II, the blood banked in the reinfusion bag for the first 6 postoperative hours was transfused back to the patient. The remaining blood collected thereafter was discarded and the drain was removed on the 3rd postoperative day as well in group II. TKA was performed using a MIS technique in all patients. The implant used was Genesis II (Genesis II high-flex PS, Smith \& Nephew, Memphis, TN, USA) in 14 patients and NexGen (LPS-Flex NexGen, Zimmer) in 22 patients in group I and Genesis II in 14 patients, NexGen in 18 patients, and Stryker NRG (Stryker, Mahwah, NJ, USA) in three patients in group II.

\section{Assessments}

The mean postoperative drainage volume was defined as the total amount of drained blood until drain removal on the 3rd postoperative day. Accordingly, the total amount of blood collected in the drainage bag was recorded as the postoperative drainage volume in group I and the amount of the reinfused blood plus the blood remaining in the drainage bag in group II. Prior to autotransfusion, vital signs were examined for evidence of a febrile reaction in group II as was done before allogeneic transfusion, which showed no abnormal findings in all the patients before and after autotransfusion. In both groups, preoperative blood test was performed and postoperative blood test and drainage volume measurement were carried out from the 1st postoperative day until drain removal on a daily basis. According to the clinical guidelines provided by the 
American Society of Anesthesiologists ${ }^{12)}$ and Spence ${ }^{13)}$, allogeneic transfusion was performed in both groups if a hemoglobin level was less than $7.0 \mathrm{~g} / \mathrm{dL}$ or a symptom of anemia with any medical complication was present and a hemoglobin level was 7.0-8.0 g/ dL. Medical history data were reviewed for both groups regarding the pre- and postoperative hemoglobin level changes, total drainage volume, autotransfusion volume, allogeneic transfusion volume and frequency, and complications.

\section{Statistical Analysis}

General patient characteristics are presented as frequency and percentage for categorical variables and mean \pm standard deviation or mean for continuous variables. The chi-square test was used to determine the difference in the allogeneic blood transfusion frequency between the groups, and an independent t-test was used to assess intergroup differences in the pre- and postoperative hemoglobin level and the amount of change, autotransfusion volume and allogeneic transfusion volume. The statistical power of the study was calculated using the allogeneic blood transfusion frequency as the primary endpoint. All statistical analyses were two-sided and a $\mathrm{p}<0.05$ was considered statistically significant. The SPSS ver. 18.0 (SPSS Inc., Chicago, IL, USA) was used for data analysis.

\section{Results}

The mean tourniquet application time was 52.67 minutes (range, 43 to 65 minutes) in group I and 55.58 minutes (range, 42 to 68 minutes) in group II, showing no significant intergroup difference $(\mathrm{p}=0.144)$. The mean intraoperative hemorrhage

A

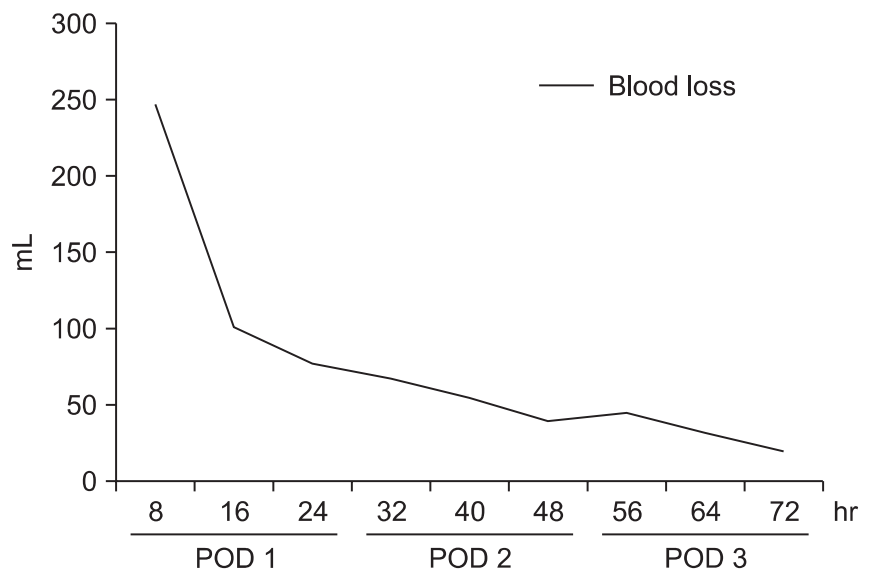

volume calculated by subtracting the amount of blood loss for wound irrigation from the total drainage volume was $500.0 \mathrm{~mL}$ (range, 32.2 to $1,145.6 \mathrm{~mL}$ ) in group I and $526.0 \mathrm{~mL}$ (range, 43.9 to $673.8 \mathrm{~mL}$ ) in group II, showing no significant intergroup difference $(\mathrm{p}=0.751)$. In particular, the value was $512.4 \mathrm{~mL}$ (range, 32.2 to $1,145.6 \mathrm{~mL}$ ) for the resurfaced knees and 496.5 $\mathrm{mL}$ (range, 47.5 to $942.2 \mathrm{~mL}$ ) for the non-resurfaced knees in group I ( $\mathrm{p}=0.930$ ). In group II, the value was $524.0 \mathrm{~mL}$ (range, 43.9 to $673.8 \mathrm{~mL}$ ) for the resurfaced knees and $529.0 \mathrm{~mL}$ (range, 387.2 to $658.0 \mathrm{~mL}$ ) for the non-resurfaced knees. Thus, patellar resurfacing does not appear to have a significant influence on intraoperative blood loss $(\mathrm{p}=0.891)$.

The mean drainage volume was $682.4 \mathrm{~mL}$ (range, 70 to 1,449 $\mathrm{mL}$ ) in group I and $851.9 \mathrm{~mL}$ (range, 50 to $1,400 \mathrm{~mL}$ ) in group II ( $\mathrm{p}=0.031)$ and approximately $57 \%$ of the drained blood was reinfused (mean, $487.6 \mathrm{~mL}$; range, 50 to $600 \mathrm{~mL}$ ) in group II. The mean blood drainage volume on the 1st postoperative day accounted for $68.2 \%$ of the total drainage volume in both groups, $428.0 \mathrm{~mL}$ in group I and $575.8 \mathrm{~mL}$ in group II (Fig. 2). Although the drainage volume on the 1st postoperative day was greater in group II, the postoperative hemoglobin level was higher in group II because of the significant difference in the hemoglobin level decrease between the preoperative and the 1 st postoperative day $(25.2 \%$ vs. $11.7 \%$; $\mathrm{p}=0.013)$ (Table 1$)$. On the blood transfusion volume, the volume of allogeneic blood transfusion performed based on the afore mentioned criteria was calculated as the total transfusion volume in group I, whereas the autotransfusion volume was added to the allogeneic transfusion volume in group II. Hematopoietic stimulating agents were not administered in both groups. The mean volume of allogeneic

B

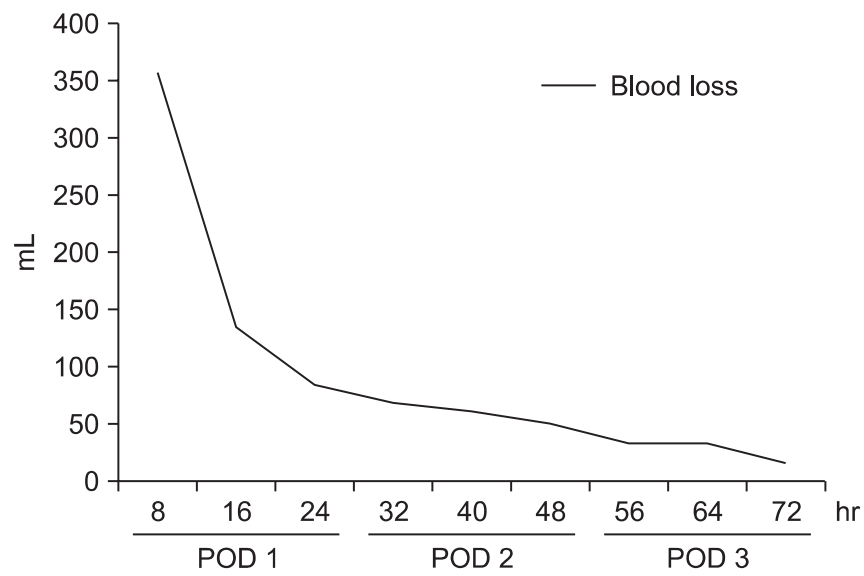

Fig. 2. The amount of drainage on the 1st postoperative day after total knee arthroplasty was $68.2 \%$ of the total amount of drainage in both groups. (A) The amount of drainage in group 1. (B) The amount of drainage in group 2. 
Table 1. Comparison of Hemoglobin Level, Group 1 and Group 2

\begin{tabular}{lrcr}
\hline \multicolumn{1}{c}{ Variable } & Group 1 & Group 2 & p-value \\
\hline $\begin{array}{l}\text { Preoperative hemoglobin } \\
\text { Postoperative hemoglobin }\end{array}$ & $12.83 \pm 1.95$ & $13.04 \pm 1.16$ & 0.574 \\
1 day & $9.60 \pm 1.36$ & $11.51 \pm 1.13$ & $<0.001$ \\
2 day & $8.85 \pm 1.15$ & $10.47 \pm 1.11$ & $<0.001$ \\
$\quad$ Last follow-up & $10.65 \pm 1.56$ & $10.47 \pm 1.08$ & 0.578 \\
Change in hemoglobin in 1 day (\%) & $22.6 \pm 24.3$ & $11.7 \pm 5.0$ & 0.011 \\
\hline
\end{tabular}

There was no significant difference in the preoperative hemoglobin level between the groups. However, the hemoglobin level on the 1st postoperative was high in the second group that received autotransfusion.

transfusion performed in 13 of the 36 patients (36.1\%) in group I was $278.9 \mathrm{~mL}$. The mean volume of allogeneic transfusion that was performed after autotransfusion in 4 patients (11.4\%) in group II was $64.4 \mathrm{~mL}$, which was $76.9 \%$ compared to that of group I indicating a statistically significant difference $(\mathrm{p}=0.004)$ (Table 2). Superficial wound infection occurred in one patient in group II, but there was no serious complication in both groups. Therefore, this study showed that postoperative blood drainage volume was not influenced by the tourniquet application time, the total hemorrhage volume including the intraoperative blood loss volume, and patellar resurfacing.

The sample size of this study was 71 patients in total (36 in group I and 35 in group II) and the primary endpoint defined as the frequency of allogeneic blood transfusion was estimated to be $36.1 \%$ in group I and $11.4 \%$ in group II. A chi-square test conducted to confirm the validity of the effect size showed the power of this study was $71.3 \%$.

\section{Discussion}

A variety of methods that can be used in place of allogeneic blood transfusion have been suggested including preoperative autologous blood donation, intraoperative normovolemic hemodilution, intraoperative blood salvage and autotransfusion, postoperative autotransfusion, and drug administration, and their efficacy on the reduction of the need for allogeneic transfusion has been well documented ${ }^{1,8,10}$. However, according to some studies, preoperative autologous blood donation was not cost-effective ${ }^{9,14)}, 70 \%$ of the banked blood was wasted without being used ${ }^{2,15)}$, and intraoperative blood salvage necessitates the use of an equipment for blood blanking ${ }^{8,16)}$. There has been disagreement on the need for drainage in TKA and its efficacy has not yet been established ${ }^{11,15)}$. Recent studies have shown that the use of an autologous drainage system designed for reinfusion
Table 2. Comparison of Allogeneic Transfusion Rate and Volume, Group 1 and Group 2

\begin{tabular}{|c|c|c|c|}
\hline Variable & Group 1 & Group 2 & p-value \\
\hline Autotransfusion volume $(\mathrm{mL})$ & $0.0 \pm 0.0$ & $487.6 \pm 124.0$ & $<0.001$ \\
\hline Allogeneic transfusion rate & $13(36.1 \%)$ & $4(11.1 \%)$ & 0.013 \\
\hline Allogeneic transfusion volume $(\mathrm{mL})$ & $278.9 \pm 378.4$ & $64.4 \pm 188.2$ & 0.004 \\
\hline
\end{tabular}

of the patient's drained blood could significantly reduce the use of allogeneic blood. Groh et al. ${ }^{17)}$, Sinha et al. ${ }^{18)}$, and Yim et al. ${ }^{19,20)}$ reported that allogeneic transfusion was less required in the autotransfusion drainage group than in the standard drainage group. In a study by Thomas et al. ${ }^{21)}$, autologous blood transfusion contributed to a decrease in allogeneic blood use and favorable cost effectiveness. In the current study, the preoperative hemoglobin level was not significantly different between the groups. On the other hand, the value on the 1st postoperative day was higher in group II who had received autotransfusion using the blood collected for the first 6 postoperative hours and allogeneic transfusion was needed in 4 of the 36 patients in the group. Therefore, we believe that the use of an autotranfusion system in TKA with an IMS technique would reduce the need for allogeneic transfusion as shown in the aforementioned studies.

However, some studies suggest that autotransfusion systems could not significantly reduce the need for allogeneic blood. Abuzakuk et al. ${ }^{22}$ reported that more than two units of allogeneic blood were required in $23 \%$ of the standard suction drainage group and $25 \%$ of the autotransfusion drainage group after TKA. However, this can be attributable to their different blood transfusion criterion of a hemoglobin level $\leq 9 \mathrm{~g} / \mathrm{dL}$. In addition, blood transfusion was performed on the 2 nd postoperative day in 11 of the 12 patients in the standard suction drainage group, whereas in 6 of the 13 patients in the autotransfusion drainage group in the study. The employment of an autotransfusion drainage system prevented the hemoglobin level from decreasing earlier, which resulted in a remarkably higher hemoglobin level on the 2 nd postoperative day in the autotransfusion drainage group. However, no statistically significant intergroup difference was found on the 5th postoperative day.

Furthermore, the stability of autotransfusion systems has been addressed in a variety of studies. In a study by Wixson et al. ${ }^{23)}$ on the red blood cell survival and coagulopathy after TKA, the red blood cell survival rate was $66 \%$ on the 3 rd postoperative day in patients who had received autotransfusion from their wound drainage, showing the effectiveness of the autotransfusion 
performed on the 1st postoperative day. On the postoperative infection, Sauaia et al. ${ }^{24)}$ reported that autotransfusion systems did not result in a significant increase in the infection rates. Dalen et al. ${ }^{10)}$ prospectively assessed the body temperature changes during the first 18 hours after TKA in 21 patients. There was no additional increase in temperature during the first 2 hours after autotransfusion. Thus, they concluded that autotransfusion did not seem to be associated with fever that could cause postoperative infections.

In the current study, the mean drainage volume was $170 \mathrm{~mL}$ greater in group II than group I ( $851.9 \mathrm{~mL}$ vs. $682.4 \mathrm{~mL}$ ). This can be attributable to the difference in the thickness of the two drain types. The thickness of the standard vacuum drain was 4.8 $\mathrm{mm}$ and that of the autotransfusion drain was $6.0 \mathrm{~mm}$. It seems reasonable to assume that the amount of drained blood under the same negative pressure would be greater for the thicker drain. The drainage volume can be controlled by adjusting the negative pressure of the autotransfusion drain. However, we used a thicker drain to increase the transfusion volume within a restricted time frame under the same negative pressure.

In addition, we used an MIS technique in TKA to investigate if reducing intraoperative blood loss would improve the efficiency of the autotransfusion system by decreasing the need for postoperative allogeneic transfusion. As seen in the studies by Bonutti et al. ${ }^{11)}$ and Tria and Coon ${ }^{25)}$, MIS techniques in TKA can be expected to lower the need for allogeneic blood when an autotransfusion system is in use because surgery can be performed through a small incision, minimizing soft tissue damage and reducing blood loss, and accordingly facilitates rapid rehabilitation.

We believe that the additional employment of an autotransfusion device after TKA using an MIS technique performed by a skilled surgeon would improve the treatment results and reduce the need for allogeneic transfusion in patients with small intraoperative blood loss and constant drainage of blood and postoperative hemoglobin level. However, these benefits can only be obtained when the surgery is performed by a surgeon well versed in MIS techniques. One of the limitations of this study include that the use of two different devices could have affected the hemorrhage volume. In the study population selection process for the autotransfusion group, we excluded patients with the risk of a severe complication, such as thrombocytopenia, disseminated intravascular coagulation, infectious diseases, hemoglobinopathy, or renal failure based on the ethical and moral grounds. However, we think that studies involving patients with other pre-existing conditions should be conducted in the future. In addition, selection bias and information bias inherent in retrospective study design might have affected the statistical analysis. In an attempt to reduce the biases, we enrolled consecutive patients who had been treated at our institution for a certain period of time. Lastly, the power of this study that was found to be $71.3 \%$ was not sufficient to achieve significance because $80 \%$ is considered adequate power in general.

\section{Conclusions}

We believe that the use of an autotransfusion system after minimally invasive unilateral TKA is beneficial for reducing the need for allogeneic transfusionin patients with no medical complications.

\section{Conflict of Interest}

No potential conflict of interest relevant to this article was reported.

\section{References}

1. Bezwada HP, Nazarian DG, Henry DH, Booth RE Jr. Preoperative use of recombinant human erythropoietin before total joint arthroplasty. J Bone Joint Surg Am. 2003;85:1795-800.

2. Rosenblatt MA, Cantos EM Jr, Mohandas K. Intraoperative hemodilution is more cost-effective than preoperative autologous donation for patients undergoing procedures associated with a low risk for transfusion. J Clin Anesth. 1997;9:26-9.

3. Slagis SV, Benjamin JB, Volz RG, Giordano GF. Postoperative blood salvage in total hip and knee arthroplasty: a randomised controlled trial. J Bone Joint Surg Br. 1991;73: 591-4.

4. Dodd RY. The risk of transfusion-transmitted infection. N Engl J Med. 1992;327:419-21.

5. Dodd RY, Barker LF. Early markers of HIV-1 infection in plasma donors. JAMA. 1989;262:92-3.

6. Lemos MJ, Healy WL. Blood transfusion in orthopaedic operations. J Bone Joint Surg Am. 1996;78:1260-70.

7. Myhre BA. Fatalities from blood transfusion. JAMA. 1980; 244:1333-5.

8. Goulet JA, Bray TJ, Timmerman LA, Benson DR, Bargar WL. Intraoperative autologous transfusion in orthopaedic patients. J Bone Joint Surg Am. 1989;71:3-8.

9. Etchason J, Petz L, Keeler E, Calhoun L, Kleinman S, Snider 
C, Fink A, Brook R. The cost effectiveness of preoperative autologous blood donations. N Engl J Med. 1995;332:71924.

10. Dalen T, Nilsson KG, Engstrom KG. Fever and autologous blood retransfusion after total knee arthroplasty: a prospective study of 40 autotransfusion events in 21 patients. Acta Orthop Scand. 2002;73:321-5.

11. Bonutti PM, Mont MA, Kester MA. Minimally invasive total knee arthroplasty: a 10-feature evolutionary approach. Orthop Clin North Am. 2004;35:217-26.

12. Practice guidelines for blood component therapy: a report by the American Society of Anesthesiologists Task Force on Blood Component Therapy. Anesthesiology. 1996;84:73247.

13. Spence RK. Surgical red blood cell transfusion practice policies: Blood Management Practice Guidelines Conference. Am J Surg. 1995;170:3S-15S.

14. Kruskall MS, Yomtovian R, Dzik WH, Friedman KD, Umlas J. On improving the cost-effectiveness of autologous blood transfusion practices. Transfusion. 1994;34:259-64.

15. Bierbaum BE, Callaghan JJ, Galante JO, Rubash HE, Tooms RE, Welch RB. An analysis of blood management in patients having a total hip or knee arthroplasty. J Bone Joint Surg Am. 1999;81:2-10.

16. Semkiw LB, Schurman DJ, Goodman SB, Woolson ST. Postoperative blood salvage using the Cell Saver after total joint arthroplasty. J Bone Joint Surg Am. 1989;71:823-7.

17. Groh GI, Buchert PK, Allen WC. A comparison of transfusion requirements after total knee arthroplasty using the Solcotrans autotransfusion system. J Arthroplasty. 1990;5:
281-5.

18. Sinha A, Sinha M, Burgert S. Reinfusion of drained blood as an alternative to homologous blood transfusion after total knee replacement. Int Orthop. 2001;25:257-9.

19. Yim SJ, Lee SH, Jang MS, Song HS, Yoon JH. An autotransfusion device reduces the amount of allogenic transfusion in bilateral sequential total knee arthroplasty. J Korean Knee Soc. 2011;23:27-32.

20. Yim SJ, Shin DH, Kim MY, Kim YB, Kim EH, Lee BI. Effect of autotrasfusion device affecting allotransfusion after total knee arthroplasty. J Korean Knee Soc. 2005;17:246-51.

21. Thomas D, Wareham K, Cohen D, Hutchings H. Autologous blood transfusion in total knee replacement surgery. $\mathrm{Br}$ J Anaesth. 2001;86:669-73.

22. Abuzakuk T, Senthil Kumar V, Shenava Y, Bulstrode C, Skinner JA, Cannon SR, Briggs TW. Autotransfusion drains in total knee replacement: are they alternatives to homologous transfusion? Int Orthop. 2007;31:235-9.

23. Wixson RL, Kwaan HC, Spies SM, Zimmer AM. Reinfusion of postoperative wound drainage in total joint arthroplasty: red blood cell survival and coagulopathy risk. J Arthroplasty. 1994;9:351-8.

24. Sauaia A, Alexander W, Moore EE, Stevens BR, Rosen H, Dunn TR. Autologous blood transfusion does not reduce postoperative infection rates in elective surgery. Am J Surg. 1999;178:549-55.

25. Tria AJ Jr, Coon TM. Minimal incision total knee arthroplasty: early experience. Clin Orthop Relat Res. 2003;(416): 185-90. 